\title{
Heterogeneidade temática e usos da memória de uma experiência histórica: uma visita ao Museu Digital da Memória Afro-Brasileira e Africana
}

\author{
Thematic heterogeneity and uses of \\ memory of a past experience: a visit to the \\ Museu Digital da Memória Afro-Brasileira e Africana
}

Luciano Magela Roza*

\section{Resumo}

Considerando-se o museu na contemporaneidade como um espaço de luta política e cultural pela afirmação da diversidade, o artigo busca discutir algumas potencialidades do Museu Digital da Memória Afro-Brasileira para a problematização dos dilemas enfrentados na efetivação da Lei 11.645/2008 no Ensino de História.

Palavras-chave: ensino de História; memórias e histórias afro-brasileiras; museus digitais.

\begin{abstract}
Considering that the museums, in the contemporary time, are places of political and cultural struggle for the diversity affirmation, the article aims to discuss some of the potentialities of the Museu Digital da Memória Afro-Brasileira e Africana (Digital Afro-Brazilian and African Memory Museum) to problematize the dilemmas faced on the effectuation of the Law 11.645/2008 in History teaching. Keywords: History teaching; AfricanBrazilian memories and histories; digital museums.
\end{abstract}

O tema da diversidade, especialmente a partir dos primeiros anos do século XXI, no Brasil, vem provocando movimentos voltados para evocações e "rememorações" de experiências ocorridas em diferentes temporalidades relacionadas a grupos portadores de especificidades étnico-raciais e culturais. Expressões nessa direção podem ser notadas em diferentes campos, como na educação, por meio da Lei 10.639/2003 e, posteriormente, pela Lei 11.645/2008, assim como pelas Diretrizes Curriculares associadas a tais normativas, e no campo patrimonial a partir da promulgação do decreto $3.551 / 2000{ }^{1}$

\footnotetext{
* Doutor em Educação. Universidade Federal do Vale do Jequitinhonha e Mucuri (UFVJM). lucianoroza@gmail.com
} 
Dentre as demandas emergentes nesse contexto, de um lado encontra-se a necessidade de construção de acervos e de que os fragmentos do passado possam ser evocados como indícios para a compreensão do vivido em tempo pretérito por grupos portadores de identidades étnico-raciais específicas; assim, tais fragmentos são evocados no tempo presente para darem visibilidade a facetas, sujeitos e processos ocultos, sub-representados, esquecidos do passado. De outro lado, vive-se sob o imperativo de utilização desses acervos como recurso pedagógico direcionado às ações de lembrar, bem como do dever do não-esquecimento público, como antídotos para questões do tempo presente e prospecção problematizadora para o futuro.

A articulação dessas duas partes, a necessidade de construção de acervos e seu atrelamento à finalidade educativa da evocação de lembranças explicitam as tensas relações entre a constituição de Lugares de Memória e o Ensino de História, assim como as relações entre memória e conhecimento histórico, e, por extensão, o conhecimento histórico escolar. Uma questão central a ser colocada relaciona-se aos usos e apropriações de arquivos, acervos, museus, monumentos - lugares de memórias - como recursos pedagógicos para a história a ser ensinada, em especial no tratamento de questões de ampla ressonância social.

Buscando contribuir para esse debate, a centralidade deste artigo reside na problematização de um acervo virtual voltado para a preservação da memória afro-brasileira e africana como uma fonte em potencial para o trabalho na sala de aula de História. Interessa-nos problematizar alguns desafios e potencialidades que esse acervo coloca ao Ensino de História.

\section{O MUSEU}

O Museu Digital da Memória Afro-Brasileira e Africana é um projeto articulado em torno de uma proposta que visa ao incentivo da produção e preservação de memórias associadas a demandas identitárias e de políticas de representação e de reconhecimento de grupos sub-representados, especialmente, aqueles de pertencimento étnico-racial africano. $\mathrm{O}$ museu busca organizar, preservar, disponibilizar e compartilhar um conjunto de arquivos digitais e exposições virtuais sobre a experiência histórica de africanos e afro-brasileiros em diferentes temporalidades históricas e espaços geográficos, que 
tem como interfaces processos de musealização, patrimonialização e disponibilização em rede.

Trata-se de um projeto de amplitude nacional, coordenado pelo antropólogo Lívio Sansone, da Universidade Federal da Bahia (UFBA), e que congrega quatro iniciativas regionais interconectadas em rede, localizadas nos estados do Rio de Janeiro, Bahia, Pernambuco e Maranhão. ${ }^{2}$

Apesar das especificidades apresentadas pelas iniciativas regionais, os objetivos do Museu Digital da Memória Afro-Brasileira e Africana buscam a preservação e a reunião de acervos relativos aos Estudos Afro-Brasileiros, de registros da cultura popular afro-diaspórica, dispersos em diferentes instituições públicas e em coleções particulares, tanto no Brasil como na África, e a digitalização, inventariação, disponibilização em formato virtual e on-line de tais acervos.

O acervo do museu é composto por conjunto amplo e diversificado de documentos que inclui fontes orais, escritas, audiovisuais e iconográficas. Vídeos, arquivos sonoros, arquivos digitalizados de periódicos, fotografias, poemas, documentos pessoais, cartas, atas, textos originais e não publicados, poesias, receitas, entrevistas, orações e rezas, composições musicais e cantigas populares, reproduções de objetos ou artefatos da cultura material são exemplos da vasta documentação mantida pelo Museu Digital.

Além disso, as coleções permanentes que compõem o museu, em suas Galerias regionais, apresentam considerável variedade de temas relacionados à memória afro-brasileira, tais como religiões de matriz africana e catolicismo negro no Brasil, manifestações da cultura popular, quilombos, comunidades negras rurais, práticas da vida cotidiana urbana e rurais, ativismo político negro, cotidiano e práticas de sociabilidade negra no contexto do escravismo, relações políticas e culturais entre Brasil e África lusófona, dentre outros.

Como podemos observar no excerto a seguir, retirado do Museu AfroDigital do Rio de Janeiro, que traz o anúncio de exposições, como aquelas sobre a negritude e pós-africanidade em comunidades de descendentes de haitianos nos Estados Unidos na atualidade, sobre remanescentes de quilombos no estado do Rio de Janeiro, e sobre as abordagens da prática da capoeira na imprensa carioca durante as décadas de 1950 e 1960, dentre outras - a variedade de temáticas abordadas no museu. 


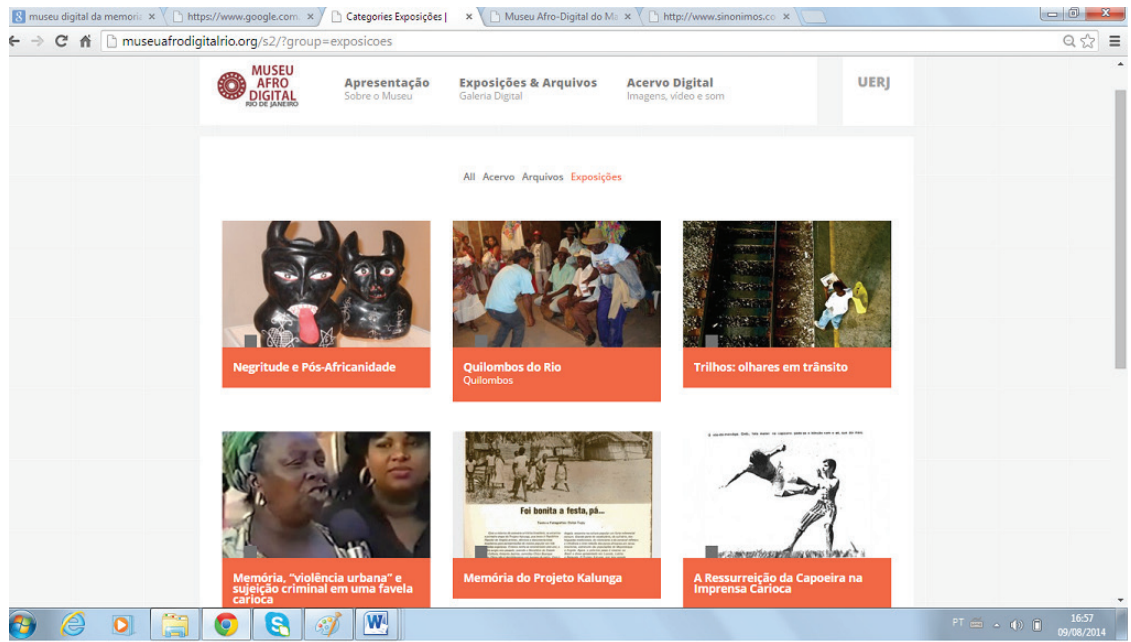

Outro aspecto do acervo relaciona-se às múltiplas temporalidades que os temas abarcam. Não há dúvida de que a dimensão da memória, tanto a relativa à sua evocação quanto aquela relativa à sua recepção e uso, é fator significativo na articulação de múltiplas temporalidades. No entanto, a composição do acervo parece trabalhar com uma concepção alargada de patrimônio que, por um lado, propõe uma fratura na ideia de que os museus são espaços que guardam o que é distante espacial e temporalmente no devir temporal, e, por outro, possibilita a percepção de que diversas manifestações do tempo presente tornem-se patrimonializadas, recaindo novamente na questão elementar das escolhas do que deve ser lembrado e do que pode ser esquecido, pois, mesmo que tudo possa potencialmente ser patrimonializado, nem tudo de fato o será.

Desta forma, o museu busca dar visibilidade a diversas experiências históricas afro-brasileiras e africanas como uma resposta às políticas de esquecimento público, socialmente compartilhadas por diferentes estratos sociais, gestadas e colocadas em prática por meio das representações presentes nos museus em diferentes momentos da história brasileira. ${ }^{3}$

Assim,

Segundo o Observatório de Museus e Centros Culturais (OMCC), programa associado ao Sistema Brasileiro de Museus, o Brasil conta hoje com mais de 2,5 mil museus. É incontestável que a maior parte desses museus foi construída sob as diretrizes de uma política nacionalista voltada para a construção de uma identi- 
dade homogênea e única, em que predominavam os sinais positivos associados à branquitude ...

Os "negros", ainda hoje, ou não aparecem nesses museus ou são representados pelo escravo submisso e/ou de forma estereotipada. Surgem como os "negros de alma branca" que contribuíram para a cultura popular, como o futebol, samba e carnaval. ${ }^{4}$

A opção de construção de uma proposta museal em espaço virtual articula-se especialmente às possibilidades apresentadas por esse tipo de suporte midiático de democratizar o acesso aos conhecimentos acumulados sobre a memória, promovendo a descentralização das formas de conhecimento por meio da construção de novas linguagens em ambiente virtual e a construção de canais de debates e trocas entre o público interessado na temática da experiência histórica e na memória afro-brasileira e africana. Nesse sentido, o almejado não é a construção de arquivos digitais disponibilizados on-line, mas sim de uma instituição ambientada em espaço virtual que contemple os pressupostos de um museu tradicional, ou seja, uma instituição permanente, sem fins lucrativos, a serviço da sociedade e do seu desenvolvimento, aberta ao público e que adquire, conserva, investiga, difunde e expõe os testemunhos materiais do homem e de seu entorno, para educação e deleite da sociedade. ${ }^{5}$ No entanto, é preciso estabelecer diferenças entre a proposta de musealização em ambiente virtual e a simples constituição de arquivos disponibilizados on-line.

De acordo com Cunha,

A primeira delas é o fato de que há uma linha tênue que separa um museu digital de um arquivo digital. A primeira fase do processo de criação de um museu com estas características precisa articular-se em torno de um arquivo, mas, efetivamente, se desejamos criar um museu, precisamos ir além do formato de espaço de arquivamento e difusão de fontes digitalizadas.

A médio e longo prazos, para que esta coleção de documentos possa receber o título de Museu Digital, esta instituição precisa realizar ações relacionadas à cadeia operatória intrínseca à instituição museu e suas ações museológicas. (Cunha, 2012, p.249) 
A cadeia operatória da museologia é organizada por ações relacionadas à salvaguarda (aquisição de acervo, estudo, documentação, tratamento e preservação) e à difusão (exposição, ação educativa e cultural, publicações). Assim, com o objetivo de criar museus digitais, apenas, as instituições compõem acervos documentais disponibilizados on-line. Nesse sentido, a proposta do Museu Afrodigital dialoga também com a perspectiva museológica de pensar o museu a partir do viés difundido pela nova museologia, a qual considera que o processo museológico e o contexto da prática museológica são mais importantes que o produto final ou o objeto exposto no museu como tal.

Criam-se, neste novo contexto, novos museus comunitários, pontos de memória, eco-museus, museus móveis, museus que criam seu acervo junto ao público e, em geral, museus das culturas popular e/ou subalternas (Sansone, 2012, p.330).

Por certo, a perspectiva de ampliação do acesso a acervos, posta pela existência de museus que veiculam seus conteúdos on-line e gratuitamente, potencialmente coloca os museus virtuais em uma posição privilegiada nos novos arranjos sociais e culturais que organizam o mundo em que vivemos. De acordo com Silva (2012), com a rápida expansão da internet na última década do século XX, os museus deixam de ser lugar em que uma pequena elite celebra suas memórias coloniais e passam a ser arenas de luta e reivindicações pós-coloniais. Diante de tal assertiva, buscamos, a seguir, problematizar dois aspectos presentes no Museu da Memória Afro-Brasileira e Africana em uma possível relação com o Ensino de História, quais sejam: a superação do lugar reservado aos afro-brasileiros e aos africanos na memória histórica e na história nacional restrita à experiência histórica do cativeiro, e os usos do passado empreendidos pelo não-esquecimento dessas experiências no presente.

\section{Muito ALÉM DA ESCRAVIDÃo}

O lugar do Ensino de História prescrito pela legislação educacional anteriormente apontada considera essa área de conhecimento como um lugar estratégico para o desenvolvimento de propostas e ações voltadas para uma reeducação das relações étnico-raciais. No entanto, uma das inquietudes docentes recorrentes trata do acesso às fontes de informação que sustentem a 
prática docente de forma reflexiva e crítica e que possibilitem o acesso à história e à memória ultrapassando o paradigma do escravismo.

De acordo com Mattos (2003, p.134), historicamente, o discurso reservado ao afro-brasileiro na memória coletiva do país e na narrativa nacional os colocou em um "lugar encapsulado". Trata-se da leitura da experiência histórica afro-brasileira circunscrita, limitada e "encapsulada" no estereótipo da mão de obra localizada no contexto da escravidão, que só atribui visibilidade ao passado do negro no Brasil como força de trabalho, seja fazendo funcionar a economia, seja desregrando a ordem social pela rebeldia supostamente cega, sem projeto político.

Os diálogos entre a evocação de memória de grupos subalternizados e o ensino de história possibilitados pelo acervo do Museu Afrodigital, se considerada a amplitude de temas, sujeitos e episódios históricos que abrange, são bastante significativos para a tentativa de superação da condição estereotipada relegada aos afrodescendentes no passado brasileiro.

A diversidade de temas considerados a serem rememorados pelo museu, localizados no passado e no presente, faz que a ideia de lugar encapsulado seja superada. Promove-se, dessa forma, um movimento elementar para a constituição de lembranças e referências positivadas acerca da experiência histórica afro-brasileira. No entanto, ao pensarmos em um ensino de história voltado para uma reflexão crítica sobre o pretérito, somente o trabalho de rememorar não basta.

Como disciplina escolar em que o imperativo da reflexão crítica sobre o passado é (ou deveria ser) um dos nortes de sua prática pedagógica, é desejável que a tentativa de resgatar a historicidade dos acontecimentos seja objeto de debate da História escolar. Nesse sentido, o acervo pode contribuir para a compreensão da historicidade em torno do protagonismo afro-brasileiro, a resistência cultural e antirracista de diferentes grupos organizados localizados em tempos e espaços diversos. A busca por compreender as posições dos sujeitos no passado, tentando compreender as formas como organizavam suas ações, no campo material e simbólico, pode ser uma proposta para a apropriação didática do acervo do museu. Perceber como pais de santo, integrantes dos movimentos negros contemporâneos, cativos do século passado etc., ou seja, afrodescendentes de contextos diversos, vivenciavam a discriminação racial, posicionavam-se em relação a ela, pode ser uma proposta significativa para a 
percepção das similaridades e diferenças, continuidades e rupturas na luta antirracial que historicamente ocorre entre nós. Essas opções narrativas rompem com a ideia de que, por um lado, a memória coletiva deve ser compreendida como correia transmissora entre o passado e o presente de forma linear e inquebrável e, por outro, desmonta concepções reducionistas que apresentam a atuação reivindicatória afro-brasileira como apenas uma versão local e vulgarizada de uma matriz identitária negra estadunidense tal como formulada por Pierre Bourdieu e Loïc Wacquant (2002). Esses autores argumentam que expressões culturais afro-americanas são exportadas para diferentes contextos como parte da política expansionista do "imperialismo ianque", o que faz de tais expressões parte da hegemonia afro-norte-americana no campo das políticas culturais afro-diaspóricas e vaticina que "os afro-brasileiros não passariam de meros receptores e reprodutores passivos de influências externas”. Em oposição à assertiva de Bourdieu e Wacquant, a título de exemplificação, uma mirada nos acervos das diferentes iniciativas regionais da instituição museal em questão, tais como a exposições fotográficas sobre manifestações culturais do Tambor de Mina e do Tambor de Crioula, produzidas em 1938, que evidenciam seus participantes, assim como os instrumentos utilizados; o conjunto de desenhos sobre a Encanteria, produzido pelo artista plástico Ciro Falção no final do século XX, presentes no Museu Afro-Digital do Maranhão, ${ }^{6}$ assim como os arquivos sobre a "memória da capoeira" e o "cotidiano negro e escravo" e as exposições "Yemanjá: A Dona do Rio" e "Memórias do Projeto Kalunga", disponibilizados pelo Museu Afro-Digital do Rio de Janeiro, colocam em relevo a heterogeneidade de experiências históricas e práticas sociais e culturais afro-brasileiras que não se ancoram na lógica de trânsito cultural supostamente articulada e dependente do imperialismo ianque.

Em relação ao Ensino de História, o acervo do Museu da Memória AfroBrasileira e Africana pode auxiliar na construção de práticas pedagógicas que possibilitem não só dar visibilidade à experiência afro-brasileira em uma perspectiva temporal, mas, também, reposicionar o lugar ocupado pelos negros na narrativa nacional, sem, contudo, perder a especificidade do tipo particular de história - neste caso, a afro-brasileira -, além de interrogar leitura hegemônicas acerca do passado nacional.

As propostas investigativas ou mesmo didáticas que procuraram "recuperar" histórias e memórias outrora invisibilizadas, sem, contudo, limitar-se 
ao movimento de apenas tornar visível a presença afro-brasileira ou africana em determinado período histórico, fazem-se bastante instigantes, do ponto de vista pedagógico, e buscam superar o alerta dado por Joan W. Scott. Ao problematizar a escrita da História produzida com vistas à visibilidade de grupos identitários, Scott (1998) adverte que uma tendência presente nos estudos comprometidos com a recuperação do passado de grupos invisibilizados, tais com negros, mulheres e homossexuais, entre outros, é a simplificação das experiências históricas por meio de homogeneizações e de uma relativa essencialização. Além dessa tendência, também se ressalta que o ato de tornar visível pode resultar apenas celebrativo, uma vez que não coloca desafios às narrativas históricas hegemônicas. Assim, refletindo sobre a historiografia do pós-emancipação, é importante ressaltar que, quando são lançadas luzes sobre a atuação de sujeitos, entidades e movimentos organizados, o que se busca, além da visibilidade, é oferecer interpretações inovadoras e promover deslocamentos na forma como determinadas interpretações do passado, especialmente a republicana universalista, se tornaram hegemônicas.

Parece-nos que essa pode ser uma perspectiva de trabalho pedagógico com o acervo em questão bastante propositiva no sentido de superação de práticas que se limitam a tornarem-se lugares reservados à vitimização dos negros ou à denúncia das adversidades vivenciadas por eles, bem como espaço dedicado à exaltação e à celebração de ícones desse passado particular. Em vez disso, eles procuram ampliar as interpretações do passado dadas a conhecer, sentir, refletir por meio do museu, com a incorporação de novos sujeitos históricos. Partindo desse pressuposto, a experiência pretérita dos afro-brasileiros ganha centralidade, como uma das facetas fundamentais para a reflexão acerca dos embates travados em torno dos sentidos e significados de raça, trabalho e cidadania construídos por tais sujeitos a partir do final do século XIX no Brasil.

\section{Memória COMo Dever ou COMO FONTE}

A complexa relação entre o trabalho da memória e a escrita da história, e os desdobramentos de tal relação para o Ensino da História, são o último aspecto suscitado nesta análise pelo Museu Digital da Memória Afro-Brasileira e Africana a ser problematizado. 
O Museu Afrodigital, ao definir a centralidade de suas ações na pesquisa, montagem e organização de acervos e exposições e a difusão de memórias circunscritas à experiência negro-brasileira e africana, opera diretamente com a ideia de que o trabalho de rememorar e do não-esquecimento é um dever, uma obrigação. Nesse sentido, a obrigatoriedade do não-esquecimento torna-se um imperativo político e moral, e, portanto, um “dever de memória”.

A noção de "dever de memória" refere-se a um conjunto de ações de reparação e reconhecimento por parte do Estado e da sociedade (Abreu, 2012; Heymann, 2007; Lalieu, 2001). Ambos devem garantir a grupos vitimados por acontecimentos e processos opressivos e traumáticos ocorridos em algum momento, em determinada sociedade ou país, que suas memórias e histórias particulares não sejam esquecidas. Ao contrário, tais memórias devem ser lembradas e reconhecidas em sua especificidade, como parte constitutiva das histórias nacionais.

Segundo Heymann (2007),

a afirmação do dever de memória se refere, portanto, à ideia de que cada grupo social, outrora vítima e hoje herdeiro da dor, pode reivindicar não só o direito de celebrar seus mártires e heróis, mas também o reconhecimento pelos danos sofridos e alguma forma de reparação. Defender o dever de memória é, pois, afirmar a obrigação que tem um país de reconhecer o sofrimento imposto a certos grupos da população, sobretudo quando o Estado tem responsabilidade por esse sofrimento. (Heymann, 2007, p.21)

Assim, nas sociedades democráticas ocidentais que sofreram, sobretudo, a partir da segunda metade do século XX, uma série de interferências que proporcionaram o advento da percepção de que não podiam ser compreendidas, do ponto de vista racial, cultural, de gênero e étnico, como um conjunto de indivíduos de origens e pertencimentos identitários homogêneos, a ideia de "dever de memória" passou a ser agenciada por grupos portadores de identidades específicas, em um duplo sentido. De um lado, como estratégia de luta política no campo do simbólico, com o objetivo de construção de ações memorialistas capazes de gerar entendimentos acerca da culpabilidade, do Estado e/ou da sociedade, em torno dos atos opressivos empreendidos contra grupos particulares em contextos específicos. De outro, buscando produzir repercussões de natureza reparatória em campos diversos como o político, o histórico, 
o jurídico, o financeiro, o educacional e o midiático. Segundo Heymann (2007), o que se observa, então, em linhas gerais, é a busca de reconhecimento e legitimidade por parte de grupos que, destacando-se da "comunidade nacional", passam a definir-se a partir de novas categorias, sejam elas étnicas, religiosas, de gênero etc.

Ao levarmos em consideração a construção histórica de práticas e representações de natureza discriminatória levadas a cabo na sociedade brasileira, o trabalho de rememoração e de construção de lembranças positivadas associadas à identidade negra no Brasil, tal como pressupõe o "dever de memória" (como estratégia política e cultural antirracismo), se faz justificável e legítima dentro de um contexto de ampliação da cidadania que, dentre seus interesses, busca promover ações de intervenção e combate a questões socialmente vivas e ainda sensíveis no presente. No entanto, somente o fato do resgate das sombras do esquecimento a sujeitos, objetos, episódios, fatos, datas etc. não é garantia de um posicionamento crítico sobre tais fragmentos do passado.

Não há dúvida de que o acesso à diversidade de memórias e histórias que compõem dada experiência histórica, tal como propõe o Museu Afrodigital, possibilita a acessibilidade, e é um elemento fundamental para a construção de práticas significativas de ampliação da cidadania de forma a articular acesso à pluralidade de experiências pretéritas selecionadas como memoráveis. Mas a evocação do passado não deve ser recebida de forma passiva, como se o passado fosse um dado absoluto, sem possibilidade de problematizações.

Uma reflexão importante relativa ao ato de constituição de um acervo museal, tanto para a versão tradicional como para a configuração virtual dessa instituição de preservação da memória, é que tal acervo nunca é um fato natural. Ao contrário, trata-se sempre de um ato de criação e elaboração discursiva, construído em torno de objetos selecionados pelo acaso do tempo e selecionados pelo trabalho humano ancorado no desejo de definir o que é digno de ser lembrado. Nesse sentido, uma ponderação elementar relaciona-se à compreensão de que, mesmo que o acervo apresente uma fonte potencial para a compreensão da experiência histórica afro-brasileira e africana, trata-se de um acervo que foi organizado a partir de interesses diversos e, portanto, resultado de diversas intervenções, e não uma fonte límpida ao passado de pertencimento africano tal como teria ocorrido. 
Nesse sentido, as relações tensas entre memória e história ganham o centro do debate. A desqualificação atribuída à primeira, acusada de militante e ilusória, em contraposição à história, compreendida como comprometida com a veracidade, mantém-se viva na medida em que a afirmação do dever de memória pode colocá-la, simplesmente, como instrumento da luta contra o esquecimento.

Na produção historiográfica contemporânea, sobretudo a partir da de Pierre Nora (1993), o distanciamento entre história e memória nos domínios da história como campo de conhecimento comparece de forma clara. Porém, de acordo com Hartog (2013, p.158), tal fratura entre essas formas de visitar o passado vem de longa data. De acordo com Hartog, desde Tucídides - que considerava a memória como um espaço de lembranças não confiável, uma vez que ela é dada ao esquecimento, a deformação do ocorrido e a sedução do prazer de agradar àquele que a escuta -, passando pela história-ciência do século XIX, que procurava o estatuto de verdade para seu reduto disciplinar.

Por essa perspectiva, o estatuto de cientificidade almejado e procurado pela história dos historiadores, e que mantém grande ressonância no Ensino de História, relega à memória o lugar de fonte, de evidência e vestígio que possibilita a composição de um cenário narrativo acerca do pretérito.

O conhecimento histórico pressupõe um trabalho teoricamente orientado e constantemente submetido a critérios publicamente discutidos e constantemente passíveis de crítica e autocrítica. A memória é algo muito mais abrangente, vincula-se ao modo pelo qual as culturas fazem relações entre passado, presente e futuro. Enquanto a história criou o hábito de pensar sobre suas fontes e suas considerações, a memória encarrega-se de lembrar, com a crença de trazer ao presente o que se passou ou ainda se passa, a partir de certos valores que podem, ou não, reivindicar validade universal. A história, sobretudo nas últimas décadas, trata a memória como objeto de estudo, como fonte para reflexões sobre o modo pelo qual as sociedades lembram, como documento sobre o papel das recordações nas várias dimensões da vida cotidiana, como a religião, a política, a família, a festa etc. O contrário não se dá, ou seja, a memória não estuda a história, assim como a saúde não estuda a medicina. Desse modo, cabe perguntar sobre as responsabilidades da história diante da memória. Francisco Régis Lopes Ramos problematizando os efeitos da memória no ensino de História na atualidade indaga: 
Transformada em bandeira de luta, dentro e fora das salas de aula, a atual "defesa da memória" vem gerando uma confusão que deve ser melhor discutida. Refiro-me à volta de narrativas que identificam o passado com a "testemunha", com base na própria legitimidade da memória. Urge, então, o debate sobre a chamada "diversidade da memória", que, em princípio, não tem (ou não deveria ter) relação de semelhança com escrita da história. Depois do longo século XX, pelo menos uma conclusão parece ser mais ou menos consensual entre os teóricos: a história não é escrita com o intuito de exibir as variações mnemônicas e sim no vínculo inegociável com problematizações sobre as relações que o presente estabelece com o passado, incluindo aí as maneiras de lembrar socialmente compartilhadas, em jogos de acordos e disputas. (Ramos, 2010)

A proposta do Museu Afrodigital ao eleger a memória como elemento central de sua organização traz para o debate essas duas facetas do trabalho de rememoração, que se apresenta bastante potente para o ensino-aprendizagem da história afro-brasileira e africana que tenha entre suas finalidades a construção de valores e posicionamentos comprometidos com pressupostos democráticos. De um lado, tomando o imperativo do moral e político do "dever de memória", lança luz sobre aspectos pouco lembrados da experiência histórica negra; de outro, faz da memória fonte de acesso, relativamente facilitado, para as apropriações e recepções diversas de pesquisadores, professores, alunos etc.

Nesse sentido, o acervo virtual disponibilizado em sala de aula pode ser uma possibilidade de uso e apropriação, território propício à caça, na tentativa de contraposição às ideias de essencialização dos testemunhos. Possibilita-se assim seu uso de forma a compor um cenário em que diversas fontes relacionadas à memória afro-brasileira podem ser articuladas no trabalho pedagógico de dar visibilidade à história afro-brasileira. Pelas fontes, torna-se possível contrapô-las, historicizar sujeitos, contextualizar práticas acessadas por tais documentos.

Tratar o dever de memória apenas como um conjunto de ações memorialistas que se abate sobre o território da história como uma possibilidade de que memórias relegadas ao esquecimento sejam lembradas, como uma espécie de particularismo em contraposição ao universalismo da História, é reduzir significativamente a discussão em tela, assim como desconsiderar as relações entre demandas socialmente vivas e a produção historiográfica, de modo estendido, ao Ensino de História. 
A emergência do "dever de história" pode ser compreendida como mais uma possibilidade de tornarem dignos de lembranças passados esquecidos. No entanto, a reflexão de Phillipe Joutard (1998) que coloca em relevo o dever ou direito à história faz-se fundamental para a compreensão acerca de como a história como campo investigativo vem dialogando com o dever de memória. Segundo Joutard (1998) citado em Pinson (2007, p.34),

Em um Estado de direito e numa nação democrática, é o dever de história, e não o dever de memória, que forma o cidadão. Porque a história ... implica distanciamento, questiona os estereótipos e, sobretudo, debate e diversifica os pontos de vista. Ela preserva do maniqueísmo e das generalizações simplistas do ódio e da intolerância. Ela possibilita a lucidez e o espírito crítico que abriga das ilusões.

Pinson (2007), corroborando Joutard, mas deslocando o foco para a História escolar, afirma que é "o dever de história que impõe o questionamento, a crítica das fontes e o rigor metodológico à leitura do passado como simples dever combater de forma mais eficaz a deriva memorialista e seus perigos" (Pinson, 2007, p.34). Nesse sentido, o dever de história seria uma garantia de que as perspectivas do passado outrora relegadas ao esquecimento, mas que agora são elevadas a aspectos do passado que devem compor a memória coletiva e a história oficial, tal como pressupõe o dever de memória, devem ser consideradas a partir da prerrogativa do olhar crítico e problematizador da História, sob o risco da criação no presente de leituras do passado e projetos de futuro em migalhas e sem lastros de veracidade histórica.

\section{REFERENNCIAS}

ABREU, Martha. Cultura imaterial e patrimônio histórico nacional. In: ABREU, Martha; SOIHET, Rachel; GONTIJO, Rebeca (Org.) Cultura politica e leituras do passado: historiografia e ensino de história. Rio de Janeiro: Civilização Brasileira, 2007. p.351-370.

. Diversidade cultural, reparação e direitos. In: MATTOS, Hebe B.; ABREU, Martha; DANTAS, C. V. (Org.) O negro no Brasil: trajetórias e lutas em dez aulas de história. Rio de Janeiro: Objetiva, 2012. p.107-112.

ABREU, Regina; CHAGAS, Mário (Org.) Memória e patrimônio: ensaios contemporâneos. Rio de Janeiro: Lamparina, 2003. 
CUNHA, Marcelo Nascimento Bernardo da. Algumas considerações sobre museus digitais. In: SANSONE, Livio (Org.) A política do intangível: museus e patrimônios em nova perspectiva. Salvador: Ed. UFBA, 2012.

Teatro de memórias, palcos de esquecimentos: culturas africanas e das diásporas negras em exposições museológicas. Anais do Museu Histórico Nacional, Rio de Janeiro, v.40, p.149-171, 2008. Disponível em: www.dominiopublico.gov.br/ pesquisa/DetalheObraForm.30999; Acesso em: 25 out. 2010.

GONÇALVES, J. R. S. Patrimônio como categoria de pensamento. In: ABREU, Ragina; CHAGAS, Mário. (Org.) Memória e patrimônio: ensaios contemporâneos. Rio de Janeiro: Lamparina, 2003.

HARTOG, François. Regimes de historicidade: presentismo e experiências do tempo. Belo Horizonte: Autêntica, 2013.

HEYMANN, Luciana Quillet. O "devoir de mémoire” na França contemporânea: entre memória, história, legislação e direitos. In: GOMES, Angela de Castro. Direitos e cidadania. Rio de Janeiro: Ed. FGV, 2007. p.15-43.

JOUTARD, Philippe. La tyrannie de la mémoire. L'Histoire, n.221, mai 1998.

LALIEU, Olivier. L'invention du devoir de mémoire. Vingtième Siècle, Revue d'Histoire, Paris, n.69, p.83-94, 2001.

LODY, Raul. O negro no museu brasileiro: construindo identidades. Rio de Janeiro: Bertrand Brasil, 2005.

MATTOS, Hebe. O ensino de história e a luta contra a discriminação racial no Brasil. In: ABREU, Martha; SOIHET, Rachel (Org.) Ensino de história: conceitos, temáticas e metodologias. Rio de Janeiro: Casa da Palavra, 2003.

NORA, Pierre. Entre memória e história: a problemática dos lugares. Projeto História, São Paulo: PUC-SP, n.10, p.7-28, 1993.

PINSON, Gérard. Enseigner l'histoire: um métier, des enjeux. Collège, lycée. Paris: Hachette Éducation, 2007.

RAMOS, Francisco Régis Lopes. As seduções da memória no Ensino de História. In: SANTOS, Lucíola Licínio de Castro Paixão [et al.] (Org.) Convergências e tensões no campo da formação e do trabalho docente. Belo Horizonte: Autêntica, 2010. v.5, p.485-508.

SANSONE, Livio. Patrimonio.Org e os dilemas da patrimonialização do intangível: da invisibilidade à hipervisibilidade de alguns aspectos da cultura afro-brasileira. In: (Org.) A política do intangível: museus e patrimônios em nova perspectiva. Salvador: Ed. UFBA, 2012.

SANTOS, Myriam Sepúlveda. A representação da escravidão. Anais do Museu Histórico Nacional, Rio de Janeiro, v.40, p.173-188, 2008. Disponível em: http://docvirt. 
com/docreader.net/docreader.aspx?bib=MHN\&pasta=\&pesq=A\%20representacao\%20da\%20escravidao.\%20; Acesso em: 25 out. 2010.

SANTOS, Myriam Sepúlveda. Entre o tronco e os atabaques: a representação do negro nos museus brasileiros. (Comunicação). In: COLÓQUIO INTERNACIONAL PROJETO UNESCO NO BRASIL: Uma volta crítica ao campo 50 anos depois. Disponível em: www.museudaabolicao.com.br; Acesso em: 31 out. 2010.

Museu digital da memória afro-brasileira: um ato de resistência. In: SANSONE. Livio (Org.) A política do intangível: museus e patrimônios em nova perspectiva. Salvador: Ed. UFBA, 2012.

. Representation of black people in Brazilian Museums. Museum Society, Leicester, v.3, n.1, p.51-65, 2005.

\section{NOTAS}

${ }^{1} \mathrm{O}$ decreto 3.551/00 institui o registro de bens culturais de natureza imaterial, que poderiam passar a constituir patrimônio cultural brasileiro, e cria o Programa Nacional do Patrimônio imaterial, no âmbito do MinC. Para a compreensão dos desdobramentos e possibilidades do conteúdo do referido decreto, ver: ABREU, 2007, p.351-370; ABREU; CHAGAS, 2003; GONÇALVES, 2003.

${ }^{2}$ Além da UFBA, as universidades UERJ, UFPE e UFMA são, respectivamente, responsáveis pelo desenvolvimento do projeto nos estados citados. Disponível em: www.arquivoafro.ufba.br/; http://museuafrodigitalrio.org/s2/; www.museuafrodigital.com.br/; www. museuafro.ufma.br/.

${ }^{3}$ Contrapontos a essa política ocorrem de forma pontual por meio de algumas instituições museais, como o Museu Afro-Brasileiro (Mafro), em Salvador, e o Museu Afro-Brasil, em São Paulo.

${ }^{4}$ SANTOS, 2012, p.280. Sobre a discussão corrente, ver também: CUNHA, 2008; SANTOS, 2008; s.d.; 2005; LODY, 2005.

${ }^{5}$ Para ter acesso a esse documento e outros, norteadores da Museologia, ver o site do Conselho Internacional de Museus: www.icom.museum.

${ }^{6}$ Disponível em: www.museuafro.ufma.br/detalhe.php?tipo_col=5; Acesso em: 14 maio 2014.

Artigo recebido em 24 de setembro de 2014. Aprovado em 23 de outubro de 2014. 